\title{
Predicting Depression among Jordanian Patients Diagnosed with Physicall Illnesses
}

\author{
Ayman M. Hamdan-Mansour ${ }^{1,2 *}$, Bushra M. Ghannam², Dana D. Al Abeiat ${ }^{3}$, \\ Talal H. Al Badawi ${ }^{4}$, Imad N. Thultheen ${ }^{5}$, Ibrahim M. Shamali ${ }^{5}$ \\ ${ }^{1}$ Department of Community Health Nursing, Al Farabi College, Riyadh, KSA \\ ${ }^{2}$ Psychiatric Mental Health Nursing, Faculty of Nursing, The University of Jordan, Amman, Jordan \\ ${ }^{3}$ Psychiatric Mental Health Nursing, King Hussein Cancer Center, Amman, Jordan \\ ${ }^{4}$ Al Farabi College, Riyadh, KSA \\ ${ }^{5}$ Department of Medical Surgical Nursing, College of Nursing, King Saud University, Riyadh, KSA \\ Email: *a.mansour@ju.edu.jo, Bushra_ghannam@yahoo.com, ddawod89@yahoo.com, \\ talal5656@yahoo.com, ithultheen@ksu.edu.sa, ishamali@su.edu.sa
}

Received 6 October 2014; revised 2 November 2014; accepted 27 November 2014

Copyright (C) 2014 by authors and Scientific Research Publishing Inc.

This work is licensed under the Creative Commons Attribution International License (CC BY).

http://creativecommons.org/licenses/by/4.0/

c) (i) Open Access

\begin{abstract}
Depression is associated with increased medical morbidity and mortality among patients with chronic medical illnesses. The purpose of this study was to investigate the psychosocial predictors of depression among patients diagnosed with chronic illnesses in Jordan. A cross sectional survey using 806 patients diagnosed with chronic illnesses has been used to collect data in regards to depressive symptoms, psychological distress, coping, optimism, life satisfaction, and perceived social support. $27.5 \%$ of the patients reported that they had moderate to severe depressive symptoms, and about $31 \%$ of them had mild level of depression. Psychological distress, perceived social support from family, life satisfaction and optimism were significant predictors of depressive symptoms $\left(\mathrm{R}^{2}=.29 ; \mathrm{F} 11,803=29.7, p<.001\right)$. Male and female patients were significantly different in their depressive scores $(\mathrm{t}=\mathbf{- 2 . 5 7}, p=.01)$. Implication for clinical practice and research are discussed.
\end{abstract}

\section{Keywords}

Chronic Illness, Depression, Jordan, Psychosocial Health

\footnotetext{
${ }^{*}$ Corresponding author.
}

How to cite this paper: Hamdan-Mansour, A. M., Ghannam, B. M., Al Abeiat, D. D., Al Badawi, T. H., Thultheen, I. N., \& Shamali, I. M. (2014). Predicting Depression among Jordanian Patients Diagnosed with Physical Illnesses. Psychology, 5, 2120-2130. http://dx.doi.org/10.4236/psych.2014.519214 


\section{Introduction}

Chronic illness is becoming the most life devastating health problem and cause of death around the world. According to Yach and associates (2004), cardiovascular diseases are the most leading cause of death around the world followed by cancer, chronic lung diseases, and diabetes mellitus. Therefore, understanding the relationship between psychosocial wellbeing and chronic illnesses appears vital to public health assessment and health care delivery system. Health care policy makers are struggling to fulfill the requirement for patients with chronic illnesses given the increased patients' demands and cost of health care. During the last few decades, Jordan has witnessed a significant increase in number of deaths primarily due to chronic illness such as cardiovascular and cancer (Ministry of Health [WHO], 2009). Thus, the comorbidity between chronic physical conditions and psychosocial health consequences such as depressive feelings, stress, adherence, and psychosocial health concerns became common interest for health professional and researchers. According to Doumit and Nasser (2010), patients with chronic illnesses are overwhelmed with psychological stressors due to requirement related to management of their illnesses. However, patients' psychosocial status may interfere with their ability to manage their needs independently that may exacerbate their health condition (Sareen, Cox, Clara, \& Asmundson, 2005). For example, patients with chronic illnesses may suffer depressive feelings that delay their recovery and healing process (Katon, Lin, \& Kroenke, 2007). Moreover, Frasure-Smith and Lespérance (2006) found that one issue of concern among patients experiencing coronary atherosclerosis disease is the development of psychological problems such as anxiety, stress, and depression. Therefore, patients with chronic illnesses are struggling to manage their physical illnesses independently and further overwhelmed with vulnerability to increased psychosocial comorbidity (Sareen et al., 2005).

One of the significant psychosocial factors that influence patients' health conditions is depression. Number of studies connected depression to health treatment outcomes. For example, depression has been associated with increased medical morbidity, mortality, worse quality of life, risk for complications among patients with cardiac and metabolic problems (Freedland, Rich, Skala, Carney, Dávila-román, \& Jaffe, 2003; Lustman, Anderson, Freed-land, de Groot, Carney et al., 2000; De Groot, Anderson, Freedland, Clouse, \& Lustman, 2000). Furthermore, the literature showed that treatment of depression had positive outcome on patients' prognosis and quality of life, and that depressed mood lowered the force needed to cope with the chronic diseases, decreased tolerability of physical symptoms, and increased psychosocial disturbances (Frasure-Smith \& Lespérance, 2006). Previous studies also show that depression have been linked with chronic illnesses (Honyashiki, Ferri, Acosta, Guerra, \& Huang, 2011), and that patients' psychological difficulties and health care professional competency related to psychological follow up care have been linked to increased morbidity, mortality, and expenditure of health services (Wang, Demler, Olfson, Pincus, Wells, \& Kessler, 2006; Sullivan, Simon, Spertus, \& Russo, 2002). According to Katon (2003), depression contributed to $50 \%$ increase in health care cost medical illnesses.

The impact of chronic illnesses on the bio-psycho-social aspects of individual health and wellbeing cannot be interpreted solely in terms of disease process, but also relates to difficulties of individuals' adjustment to their illnesses and the evolved changes of their lifestyle (MacDonald, 2005; Chen and Chang, 2012). Therefore, understanding the relationship between depression and other psychosocial factors such as coping, social support, life satisfaction, optimism and stress seem to be noteworthy in terms of understanding the factors that interfere with effectiveness of treatment plans. Previous studies show that there is a relationship between difficulties in coping mechanisms, perceived social support and the development of depression among patients with chronic illnesses (Zhang, Chen, \& Chen, 2008). This infers that exploring factors that predict depression among patients with chronic illness will enable addressing the factors that possibly affect patients' physical and psychological condition. In Jordan, few studies addressed this issue either generally or among specific group of patients (Khalil, DarAwwad, Al-Gamal, Hamdan-Mansour et al. 2012; Hamdan-Mansour, Halabi, \& Dawani, 2009). However, information related to depression among diagnosed with chronic illnesses in Jordan is limited, provoking the need to explore the interrelationship between depression and the psychosocial factors especially with the increased cost and demands for health care services globally. Therefore, the purpose of this study is to examine the psychosocial predictors of depression among patients with chronic illnesses in Jordan. The specific aims are:

- To examine prediction power of stress, social support, life satisfaction, optimism and coping on depressive symptoms among patients with chronic illnesses in Jordan controlling for demographic and personal characteristics.

- To identify the differences of depressive symptoms of patients with chronic illnesses in Jordan in relation to 
demographic and personal characteristics: age, gender, working status, and medical diagnosis.

\section{Method}

\subsection{Design}

A quantitative approach using cross-sectional, descriptive-correlational design was used to examine. Data was data from patients diagnosed with diabetes mellitus-type-II, Rheumatoid arthritis, cardiovascular diseases (CVD), cancer, and pulmonary diseases from the three health care sectors in Jordan (governmental, University affiliated, and private). Information collected in regards to stress, depression, perceived social support, coping, optimism, and life satisfaction.

\subsection{Sample and Settings}

A convenience sampling of 806 completed and retuned the questionnaire. The study targeted patients attending primary, secondary and tertiary care units. Inclusion criteria include: 1) diagnosed with one of the following chronic illness longer than 6 months: diabetes mellitus-type-II, Rheumatoid arthritis, CAD, cancer, and pulmonary diseases; 2) age of 18 years or above; 3) ability to read and write in Arabic. Exclusion criteria included: no history of diagnosed mental or cognitive disorders.

\subsection{Data Collection Procedure}

Prior data collection, ethical approval obtained from the Faculty of Nursing at the University of Jordan, and the targeted institutions. Data collected using self report format of data collection at patient's convenience. Patients who expressed interest to participation in the study were approached by the researcher who explained the study and provided them with all details and answered all their questions. Patients were asked to sign the consent form that included information related to the title of the study, its purpose, its significance and a statement informing the participants that their privacy would be protected by assuring them that their responses will be treated confidentially, and information that reveal their identity will not be recorded. Also, the information will be used for the purpose of the study, and that their participation is voluntary and they have the right to withdraw at any time during the study and that their decision will not influence the quality of care they receive. Anonymity of the respondents ensured during and after study completion; and data secured and saved to provide anonymity. All data e kept in a closed cabinet at the Faculty of Nursing, University of Jordan. The whole package presented in Arabic language.

\subsection{Instruments}

The data collected using an Arabic version of self-reporting questionnaires. The English format of questionnaires consulted by a professional English language editor. To formulate the Arabic language format, a numbers of procedures used to determine the reliability and validity of the tool. The tool first translation into Arabic language by a research assistant and back translated into English language another independent research assistant as described by Brislin (1970) and Chapman and Carter (1979). The two English forms (the original and the translated) compared in terms of conceptual rather than literal meaning of the items by the primary and co-investigators who had the expertise in the field. The translator and the back translator meet to examine the difference in the two forms. Pilot testing conducted using patients $(n=25)$ requesting their appraisals for the appropriateness of the translation.

The Instruments were:

1) Perceived social support was measured by Multidimensional Scale of Perceived Social Support (Zimet, Dahlem, Zimet, \& Farley 1988). This scale is 12 -item self-reported scale to assess the perception of social support adequacy from the family, friends, and significant others such as health care team. Each item is measured using a 7-point Likert scale ranging from 1 (very strongly disagree) to 7 (very strongly agree). The scale has three sub scales, family (items $3,4,8, \& 11$ ), friends (items, 7, 9, \& 12), and significant others (items, 1, 2, 5, \& 10). The total score ranges from 7 to 84 . The higher the score is the higher the perceived social support. This scale had good internal consistency for the scale as whole which was .88. In this study, Cronbach's Alpha for the subscales were .85 (Family), .79 (friends), and .75 (others). 
2) The Beck Depression Inventory-II (BDI-II) (Beck, Steer, Brown, \& 1996) was used to assess patients' depressive symptoms, which contain items that measure cognitive-affective symptoms and attitudes, impaired performance, and somatic symptoms (Beck et al., 1996). This instrument contains 21 questions answered on a four-point Likert scale in which 0 represents the absence of symptoms and 3 represents an extreme problem. The total range of 0 to 63 and standard cutoff points as follow: 0 - 13 indicates no or minimal symptom, 14 - 19 indicates mild symptoms, 20 - 28 indicates moderate symptoms, and 29 - 63 indicates severe symptoms (Beck et al., 1996). A score of 13 is the cut-off point indicating depression. The test-retest $r$ was .88, and Cronbach's Alpha is .87 (Beck et al., 1996). In this study, Cronbach's Alpha was .85 .

3) Stress was measured using the brief form of Psychological Stress Measure (Lemyre, Tessier, \& Eillion, 1990). The original Psychological Stress Measure (PSM) was designed using 49 items drawn from descriptors generated by focus groups on stress. The scale is unifactorial in structure and maintains a test-retest stability of .68 to .80 under apparently constant conditions. Patients checks the answer that best indicates the degree to which each statement has applied to him/her recently The responses made on a Likert scale and ranged from range from 1 (null) to 4 (much). The higher the score in the scale reflect higher level of psychological stress. In this study, Cronbach's Alpha was .88.

4) Coping skills was measured using the abbreviated version of the COPE Inventory (Carver, 1990). Brief COPE is a 28 items scale measures the ways individuals use to cope with stress in their life. Brief COPE is formed of 14 domains (each consisted of 2 items) were responses ranged from 1 (I haven't been doing this at all) to 4 (I've been doing this a lot). The scale takes $>10$ minutes to be completed. The scale has good internal inconsistency with Cronbach’s alpha of .83 (Carver, 1990). In this study, Cronbach’s Alpha was .73.

5) Optimism was measured using the Life Orientation Test (LOT-R) (Scheier, Carver, \& Bridges, 1994). The LOT-R is designed to measure optimisms by assessing the generalized outcome expectancies of individuals. Each item is scaled on a five point Likert scale. The responses ranges from strongly agree to strongly disagree. The scoring is done by reversing the negative statement and then adding all the responses together. Cronbach's alpha for the scale was .76 and test-retest was estimated at .79 (Scheier, Carver, \& Bridges, 1994). In this study, Cronbach's Alpha was .81.

6) Life satisfaction was measured using the Satisfaction with Life Scale (Diener, Emmons, Larsen, Griffin, 1985). This is a general measure of life satisfaction, which consisted of five statements. Participants were asked to rate each statement according to the following seven-point scale: a) strongly disagree; b) disagree; c) slightly disagree; d) neither agree nor disagree; e) slightly agree; f) agree; and g) strongly agree. The scores of the total scale ranges from 5 to 35 and interpreted as follow: from 31 - 35 (eextremely satisfied), from 26 - 30 (satisfied), from 21 - 25 (slightly satisfied), 20 (neutral), from 15 - 19 (slightly dissatisfied), from 10 - 14 (dissatisfied), and 5 - 9 (extremely dissatisfied). The test-retest reliability was estimated to be .87 (Diener et al., 1985). In this study, Cronbach's Alpha was .78.

Potential covariates: Gender, age, marital status, type of disease, duration of disease, smoking status, income, Education level and work status. The demographic information obtained from an investigator-developed subject profile.

\section{Results}

\subsection{Descriptive Characteristics}

A total number of 806 patients completed the questionnaire (see Table 1). Patients' age ranged from 18 to 90 years, with mean of $51.5(S D=15)$. About $54 \%(n=436)$ of the patients there were male patients, while $45.9 \%$ $(\mathrm{n}=370)$ were females. In regard to marital status, the majority of them $73.8 \%(\mathrm{n}=595)$ were married, while $5.2 \%(n=42)$ were divorced, and $10.5 \%(n=85)$ were single, and $10.4 \%(n=84)$ were widow. The analysis also showed that most of patients $(52 \%, n=419)$ were not working, and $25.3 \%(n=204)$ of them had a full time work, also $15.3 \%(n=123)$ had retired, where the least percent $7.4 \%(n=60)$ of patients had a part time work.

In regard to their medical diagnosis, the analysis showed that $28.6 \%(\mathrm{n}=230)$ of the patients had diabetes mellitus type-II, 21.6\% $(n=174)$ had cardiovascular disease, $14.6 \%(n=118)$ had pulmonary diseases, $13.3 \%(n$ $=107)$ had rheumatoid arthritis, and $11.4 \%(\mathrm{n}=92)$ had cancer. The analysis also showed that the majority ( $70.1 \%, n=565)$ of patients were not smoking, while $29.9 \%(n=241)$ were active smokers. Among those who smoke, $25 \%(n=60)$ of them smoked more than 10 cigarettes per day. 
Table 1. Descriptive characteristics of patients diagnosed with chronic illnesses $(\mathrm{N}=806)$.

\begin{tabular}{|c|c|c|c|c|c|c|c|c|}
\hline \multicolumn{2}{|r|}{ Variable } & $\mathrm{n}$ & $\%$ & M & SD & Md. & $\mathrm{P}_{25}$ & $\mathrm{P}_{75}$ \\
\hline \multicolumn{2}{|r|}{ Age } & & & 51.5 & 15 & 52 & 41.8 & 63 \\
\hline \multirow{2}{*}{ Gender } & Male & 436 & 54.1 & & & & & \\
\hline & Female & 370 & 45.9 & & & & & \\
\hline \multirow[t]{5}{*}{ Marital status } & Single & 85 & 10.5 & & & & & \\
\hline & Married & 595 & 73.8 & & & & & \\
\hline & Widow & 84 & 10.4 & & & & & \\
\hline & Divorced & 42 & 5.2 & & & & & \\
\hline & Not working & 419 & 52 & & & & & \\
\hline \multirow[t]{4}{*}{$\begin{array}{l}\text { Working } \\
\text { status }\end{array}$} & Part-time job & 60 & 7.4 & & & & & \\
\hline & Full time job & 204 & 25.3 & & & & & \\
\hline & >High school & 365 & 45.3 & & & & & \\
\hline & High school & 171 & 21.2 & & & & & \\
\hline \multirow[t]{5}{*}{$\begin{array}{l}\text { Level of } \\
\text { education }\end{array}$} & Diploma & 120 & 14.9 & & & & & \\
\hline & Bachelor & 127 & 15.8 & & & & & \\
\hline & Graduate & 4 & .5 & & & & & \\
\hline & Diabetes mellitus & 230 & 28.6 & & & & & \\
\hline & Cardiovascular & 174 & 21.6 & & & & & \\
\hline \multirow[t]{3}{*}{$\begin{array}{c}\text { Medical } \\
\text { diagnoses }\end{array}$} & Pulmonary & 118 & 14.6 & & & & & \\
\hline & Cancer & 92 & 11.4 & & & & & \\
\hline & Rheumatoid Arthritis & 107 & 13.3 & & & & & \\
\hline \multirow[t]{2}{*}{ Smoking } & Smoking & 241 & 9.9 & & & & & \\
\hline & Not smoking & 565 & 70.1 & & & & & \\
\hline
\end{tabular}

\subsection{Psychosocial Health Factors}

Depression: Regarding depressive symptoms, the analysis (see Table 2) showed that the patients had a mean score of 16.1 ( $\mathrm{SD}=10.2$ ) with scores ranging from 0 to 54 . About $50 \%$ of the patients had a score of 16 or above. In regards to level of depression, the analysis showed that $41.4 \%(n=334)$ of the patients found to have no or minimal depressive symptoms, while $31 \%(n=250)$ had mild depressive symptoms, $15.5 \%(n=125)$ had moderate depressive symptoms, and $12.0 \%(\mathrm{n}=97)$ had severe depressive symptoms. The analysis indicates that about $25 \%$ of the patients are suffering from depressive symptoms compared to $41 \%$ with no to minimal depressive symptom.

Optimisms: Regarding patients' optimism perception using life orientation scale (see Table 2), the analysis showed that patients had a mean score of $34.5(\mathrm{SD}=5.9)$ with scores ranging from 10 to 50 . Considering that the possible range of score is $5-50$, and that the analysis showed that $50 \%(n=403)$ of the patients had a score of 34 or above and $50 \%$ of them had a score between 32 and 38, the results indicate that patients, in general, had high level of optimism.

\section{Coping skills}

Regarding patients' coping skills using brief COPE scale (see Table 2), the analysis showed that patients had a mean score of $71.6(\mathrm{SD}=10.1)$ with scores ranging from 29 to 104. Considering that the possible range of score is $28-112$, and that the analysis showed that $50 \%(n=403)$ of the patients had a score of 71 or above and 
Table 2. Psychosocial health status of patients diagnosed with chronic illness in Jordan $(\mathrm{N}=806)$.

\begin{tabular}{ccccccccc}
\hline Variable & $\mathbf{N}$ & $\mathbf{M}$ & $\mathbf{S D}$ & $\mathbf{M i n}$ & $\mathbf{M a x}$ & $\mathbf{P}_{\mathbf{2 5}}$ & $\mathbf{P}_{50}$ & $\mathbf{P}_{75}$ \\
\hline Depressive symptoms & 806 & 16.1 & 10.2 & 0 & 54 & 9 & 16 & 21 \\
Social support-other & 806 & 22.7 & 4.9 & 4 & 28 & 21 & 24 & 26 \\
Social support-family & 806 & 22.2 & 4.8 & 4 & 28 & 20 & 23 & 26 \\
Social support-friends & 806 & 18.4 & 6.2 & 4 & 28 & 14 & 20 & 23 \\
Optimism & 806 & 34.5 & 5.9 & 10 & 50 & 32 & 34 & 38 \\
Life satisfaction & 806 & 23.8 & 5.8 & 5 & 35 & 21 & 25 & 28 \\
Coping & 806 & 71.6 & 10.1 & 29 & 104 & 67 & 71 & 77 \\
Psychological distress & 806 & 41.9 & 11.3 & 14 & 68 & 33 & 42 & 51 \\
\hline
\end{tabular}

$50 \%$ of them had a score between 67 and 77 , the results indicate that patients, in general, had moderate of their ability to effectively cope with their life situations.

Life satisfaction: Regarding patients' satisfaction about their life (see Table 2), the analysis showed that patients had a mean score of 23.8 ( $\mathrm{SD}=5.8$ ) with scores ranging from 5 to 35 . Considering that the possible range of score is $5-35$, and that the analysis showed that $50 \%(n=403)$ of the patients had a score of 25 or above and $50 \%$ of them had a score between 21 and 28, the results indicate that patients, in general, had high level of satisfaction about their life.

Psychological distress: Regarding patients’ psychological distress level (see Table 2), the analysis showed that patients had a mean score of 41.9 ( $\mathrm{SD}=11.7$ ) with scores ranging from 14 to 68 . Considering that the possible range of score is $9-72$, and that the analysis showed that that $50 \%(n=403)$ of the patients had a score of 42 or above and $50 \%$ of them had a score between 33 and 51 , the results indicate that patients, in general, had moderate level of stress.

Perceived social support: Regarding patients' perception of perceived social support (see Table 2), the analysis showed that patients' highest perception of perceived social support was from others and family with mean scores of $22.7(\mathrm{SD}=4.9)$ and $22.2(\mathrm{SD}=4.8)$ respectively. However, patients had lower perception of social support from friends with score of 18.4 (SD = 6.2). In general, perception of social support from family, friends and other were at the moderate level give the possible range of score for each subscale to be 4 - 28 and the median scores for all subscales were almost equal and at the moderate to high level (23 - 26). The analysis is showing the lowest level of perception was support from friends although the scores of seem to be at the moderate level.

\subsection{Differences in Depressive Symptoms in Relation to Demographic Characteristics}

Regarding the relationship between demographic and personal characteristic and depressive symptoms, the analysis showed that although there was a negative correlation between patients' age depressive symptoms, this relationship was not statistically significant. Regarding gender differences, the analysis showed that there was significant difference between male and female patients in their depressive symptoms $(\mathrm{t}=-2.57, p=.01)$ with higher mean score of BDI among female patients $(\mathrm{M}=17.1, \mathrm{SD}=101.0)$ than male patients $(\mathrm{M}=15.2$, $\mathrm{SD}=$ 10.2). To examine the differences in psychological factors in relation to working status, one-way ANOVA was conducted. The analysis showed that there was a significant difference in depressive symptoms in regards to working status, $\left(\mathrm{F}_{3,806}=9.3, p<.001\right)$. Using post hoc comparison (scheffe), the analysis showed that that those who are not working $(\mathrm{M}=17.8, \mathrm{SD}=10.5)$ were significantly different (higher mean) in their BDI score from those working full time $(\mathrm{M}=13.5, \mathrm{SD}=8.9)$.

Regarding differences in depressive symptoms in relation to patients' medical diagnoses (see Table 3), the analysis showed that $21.6 \%(\mathrm{n}=24)$ of those diagnosed with pulmonary diseases had moderate to severe depressive symptoms, while $29.3(\mathrm{n}=48)$ of those with CVD, 47.7\% $(\mathrm{n}=40)$ of those diagnosed with cancer, $27.8 \%(n=28)$ of those diagnosed with rheumatoid arthritis, $16.7 \%(n=27)$ of those diagnosed with diabetes, and $36.1 \%(n=43)$ for those who have more than one of the listed chronic disease. 
Table 3. Difference in depression level among related to medical diagnosis $(\mathrm{N}=806)$.

\begin{tabular}{|c|c|c|c|c|c|c|c|c|c|c|c|c|c|c|}
\hline \multirow{3}{*}{$\begin{array}{l}\text { Depression } \\
\text { Level }\end{array}$} & \multicolumn{12}{|c|}{ Medical Diagnosis } & \multirow{2}{*}{\multicolumn{2}{|c|}{ Total }} \\
\hline & \multicolumn{2}{|c|}{ Pulmonary $\mathrm{d} / \mathrm{o}$} & \multicolumn{2}{|c|}{ CVD } & \multicolumn{2}{|c|}{ Cancer } & \multicolumn{2}{|c|}{ Rheumatoid Arthritis } & \multicolumn{2}{|c|}{ DM-II } & \multicolumn{2}{|c|}{ Co-morbid } & & \\
\hline & $\mathbf{n}$ & $\%$ & $\mathbf{n}$ & $\%$ & $\mathbf{n}$ & $\%$ & $\mathbf{n}$ & $\%$ & $\mathbf{n}$ & $\%$ & $\mathbf{n}$ & $\%$ & $\mathbf{n}$ & $\%$ \\
\hline Not depressed & 53 & 47.7 & 75 & 45.7 & 20 & 22.7 & 45 & 44.6 & 114 & 51.6 & 26 & 21.8 & 333 & 41.4 \\
\hline Mild & 34 & 30.6 & 41 & 25.0 & 26 & 29.5 & 28 & 27.7 & 70 & 31.7 & 50 & 42.0 & 249 & 31.0 \\
\hline Moderate & 13 & 11.7 & 29 & 17.7 & 17 & 19.3 & 15 & 14.9 & 25 & 11.3 & 26 & 21.8 & 125 & 15.5 \\
\hline Severe & 11 & 9.9 & 19 & 11.6 & 25 & 28.4 & 13 & 12.9 & 12 & 5.4 & 17 & 14.3 & 97 & 12.1 \\
\hline
\end{tabular}

The results infers that those diagnose with cancer had the highest reported depressive symptoms among all listed chronic illnesses followed by those who have more than one disease. Using one-way ANOVA to examine differences in depressive symptoms in relation to patients' medical diagnoses, the analysis showed that there was significant difference in depressive symptoms related to medical diagnoses $\left(\mathrm{F}_{5,806}=12.8, p<.05\right)$. Using post hoc comparison (Scheffe), the analysis showed that patients diagnosed with cancer are significantly different (had higher mean score; $M=21.9, S D=12)$ from all other patients; pulmonary disease $(M=14.9, S D=9.9)$, CVD $(M=15.9$, SD = 10.6), RA $(M=15.9$, SD = 10.2), and DM-II $(M=13, \mathrm{SD}=8.4)$. The results indicate that patients diagnosed with cancer had more depressive symptoms than all other patients diagnosed with chronic illness in this study.

To examine whether stress, social support, life satisfaction, optimism and coping are significant predictors of depressive symptoms among controlling for the demographic and personal characteristics (age, gender, working status, and medical diagnose), two-steps multiple hierarchical regression analysis was performed.

The results (see Table 4) showed that model 1 that contained demographics and personal characteristics explained $2 \%\left(R^{2}=.02\right)$ of the variance in depressive symptoms (see Table 4$)$. Although the $R^{2}$ was very small, the model was significant $\left(\mathrm{F}_{4,803}=3.27, p=.012\right)$. In this model, only working status was a significant predictor of depressive symptom. After entry of stress, social support, life satisfaction, optimism and coping at step 2, the total variance explained by the model as a whole was $29 \%\left(R^{2}=.29\right)$ and was significant $\left(\mathrm{F}_{11,803}=29.7, p<.001\right)$. The variables in step 2 explained an additional $27 \%$ of variance in depressive symptoms. In Model 2, working status was not a significant predictor of depressive symptoms as it was in model 1 . In addition, perceived social support from family $(\beta=-.087, p=.041)$, optimism $(\beta=-.235, p<.001)$, life satisfaction $(\beta=-.255, p<.001)$, and psychological distress $(\beta=.239, p<.001)$ were significant predictors of depressive symptoms.

\section{Discussion}

Globally, chronic physical health problems are the main cause for disability (Mathers \& Loncar, 2005), and depression is associated with increased medical morbidity, mortality, and risk for complications among patients with chronic medical illnesses (Freedland et al., 2003; De Groot et al., 2000). Depression also found to increase the health care cost even with suppression of physical severity (Katon, 2003).

Therefore; screening for psychological factors among patients diagnosed with chronic illnesses is considered a primary function for health professional caring for this group of patients (Hamdan-Mansour, 2010; HamdanMansour et al., 2012). This study aimed at examining the psychosocial predictors of depressive symptoms among patients diagnosed with chronic illnesses and explore further about the differences in depressive symptoms related to sociodemographic and medical conditions. The study found, in general, that a significant number of patients (27.5\%) had moderate to severe depressive symptoms and 31\% had mild depressive symptoms. In addition, the study showed that the depressive symptoms among the listed chronic illnesses ranged from $16 \%$ (diabetes) to $47 \%$ (cancer). The results of this study had some agreement with previous international reports. Globally, Moussavi and colleagues (2007) found that prevalence of depressive episode among patients with chronic illnesses ranged from 2.0\% (diabetes mellitus) to 4.5 (angina), and that the average depressive episode among those with more than one physical disorder ranged from $9.3 \%$ to $23.0 \%$. The prevalence of depressive symptoms in this study is higher than Moussavi and colleagues' report. One explanation is that in this study a self report format of data has been used while in Moussavi and colleagues' reported data has been collected using interviews. Moreover, this study found that about $28.5 \%$ of patients with cancer had severe depressive 
Table 4. Two steps Multiple Hierarchal Regressing depressive symptoms on stress, social support, life satisfaction, optimism and coping controlling for demographic and personal characteristics among patients with chronic illness in Jordan $(\mathrm{N}=806)$.

\begin{tabular}{ccccc}
\hline \multirow{2}{*}{ Variables } & \multicolumn{2}{c}{ Model 1} & \multicolumn{2}{c}{ Model 2} \\
\cline { 2 - 5 } Age & $\beta$ & $P$-value & $\beta$ & $P$-value \\
Gender & -.006 & .880 & .045 & .155 \\
Working status & .043 & .278 & .031 & .370 \\
Medical diagnoses & -.100 & .013 & -.051 & .138 \\
PSS-Fa & -.014 & .707 & .032 & .315 \\
PSS-Fr & & & -.087 &. $\mathbf{0 4 1}$ \\
PSS-others & & & -.060 & .094 \\
Optimism & & & .026 & .558 \\
Life satisfaction & & & -.235 & $\mathbf{. 0 0 0}$ \\
Coping & & & -.255 & $\mathbf{. 0 0 0}$ \\
Psychological distress & & & .006 & .846 \\
$R^{2}$ & .02 & .012 & .239 & .000 \\
Adjusted $R^{2}$ & .01 & & .28 & $<.001$ \\
$R^{2}$ change & - & & .27 & \\
\hline
\end{tabular}

PSS-Fr: Perceived social support from friends; PSS-Fa: Perceived social support from family; PSS-others: Perceived social support from others.

symptoms, while in previous study the prevalence rates for depression in patients with cancer ranged from $22 \%$ to $29 \%$ (Hotopf, Chidgey, Addington-Hall, \& Ly, 2002) which is indicates that patients with cancer in Jordan had almost equal rates of depressive feeling to those in other regions in the world. Moreover, and similar to Zhang and associates (2008), the majority of the patients in this study (60\% - 75\%) with pulmonary diseases, diabetes, CVD had depressive feelings. These rates were higher than what has been reported by previous studies that that 20\% of patients with COPD had depressive feeling (Di Marcoa et al., 2006), and 51\% of patients with congestive heart failure had mild to severe depressive symptoms on BDI (Freedland et al., 2003). In conclusion, significant number of patients with chronic illnesses suffers depressive feelings that may interfere negatively in their ability to adapt to their illness.

In regards to psychosocial predictors of depression, we found that perceived social support from family, optimism, life satisfaction, and psychological distress were significant predictors of depressive symptoms. Whereas, age and type of medical diagnoses were not significant predictors of depressive symptoms, there was a significant difference between male and female patients. The results support previous reports that depression is associated with number of clinical and demographic characteristic of patients diagnosed with chronic illnesses (Katon et al., 2007; Gottlieb et al., 2004; Katon, 2003), and that depression is associated with perceived social support among patients with chronic illnesses (e.g., Zhang et al., 2008). Although literature shows connection between coping to depression among patients with chronic illness (Frasure-Smith \& Lespérance, 2006; Zhang et al., 2008), this study showed that depression and coping has weak correlations and the coping is not a significant predictor of depression. This may question the role of coping mechanism in forming the psychological status of patients. One possible explanation is that patients had depressive feeling, however; they have also utilized available sources of social support and their level of satisfaction and feeling optimistic as means to manage the negative feeling resting from depression. Another explanation might be related to the intercorrelation of depressive symptoms and psychological distress and the use of social support as buffering system. According to Cohen, Gottlieb and Underwood (2000), social support influences health through either the stress-buffering model or the main effect model. The main premises of the stress-buffering model is that others will provide necessary resources that may redefine the potential for harm posed by a situation and cushions one's perceived ability to 
cope with imposed demands, thereby preventing a particular situation from being perceived as stressful. These two models provide an explanation for how an individual's physical and mental health is maintained and promoted. The individual's social support, based on the stress buffering and main effect models, influences the individual's emotions, cognition, and behaviors, and consequently; is able to perceive risk factors and functions in a healthy way that improves their level of life satisfaction and their optimistic perspectives. This may resulted in maintaining positive levels of optimism, life satisfaction and effectively using coping skills. The results also support Lewinsohn's model that patients with chronic illnesses are at risk for depression if their illness affected their ability to function (Lewinsohn, Hoberman, Teri, \& Hautzinger, 1985). In this study, patients were able to maintain their function utilizing social support that, in turn; resulted in improving their life satisfaction and optimistic view of life. In conclusion, Jordanian patients with chronic illness are suffering depression, and that improving their psychosocial health status; perceived social support, optimism, and life satisfaction and managing their stressful life events will enable patients to encounter their negative feelings that produce depression.

One limitation for this study is that data were collected cross sectional, while a longitudinal one may allow better understanding for a cumulative experience over long period of time.

\section{Conclusion}

Managing comorbidity of physical and psychological problems in primary care is needed. Data from this study suggest that there is a higher incidence and prevalence of depression in patients with chronic medical illness. Moreover, the study suggest that managing stress, enhancing social support, life satisfaction, and optimism are among the most influencing factors that encounter negative feeling and development of depression among patients with chronic illnesses. This study has an implication for psychosocial nurses and mental health professionals at the community and primary care settings. There is a need that psychosocial nurses and mental health professionals assess and screen psychosocial factors: stress, depression, social support, optimism, life satisfaction, and coping skills among patients with chronic illness in their routine checkups and visits to outpatients units. There is also a need to develop large treatment trials aimed at improving outcomes of psychosocial wellbeing in medical illnesses to prospect the cost and burden of such illnesses. Future research must focus on establishing diagnostically reliable criteria measuring depression and other psychosocial factors.

\section{References}

Beck, G., Steer, R., \& Brown, G. (1996). Manual for the Beck Depression Inventory-II. San Antonio, TX: Psychological Corporation.

Brislin, R. W. (1970) Back Translation for the Cross-Cultural Research. Journal of Cross Cultural Research, 1, $185-216$. http://dx.doi.org/10.1177/135910457000100301

Carver, C. S. (1990). You Want to Measure Coping but Your Protocol's Too Long: Consider the Brief COPE. International Journal of Behavioral Medicine, 4, 92-100. http://dx.doi.org/10.1207/s15327558ijbm0401_6

Chapman, D. W., \& Carter, J. F. (1979). Translation Procedures for Cross Cultural Use of Measurement Instrument. Education Evaluation and Public Analysis, 1, 71-76. http://dx.doi.org/10.3102/01623737001003071

Chen, P. Y., \& Chang, H. C. (2012). The Coping Process of Patients with Cancer. European Journal of Oncology Nursing, 16, 10-16. http://dx.doi.org/10.1016/j.ejon.2011.01.002

Cohen, S., Underwood, L. G., \& Gottlieb, B. H. (2000). Social Relationships and Health. In S. Cohen, L. G. Underwood, \& B. H. Gottlieb (Eds.), Social Support Measurement and Intervention: A Guide for Health and Social Scientists, New York: Oxford University Press.

De Groot, M., Anderson, R., Freedland, K. E., Clouse, R. E., \& Lustman, P. J. (2001). Association of Depression and Diabetes Complications: A Meta-Analysis. Psychosomatic Medicine, 63, 619-630. http://dx.doi.org/10.1097/00006842-200107000-00015

Diener, E., Emmons, R. A., Larsen, R. J., \& Griffin, S. (1985). The Satisfaction with Life Scale. Journal of Personality Assessment, 49, 71-75. http://dx.doi.org/10.1207/s15327752jpa4901_13

Di Marcoa, F., Vergaa, M., Reggentea, M., Casanovaa, F. M., Santusa, P., Blasib, F., Allegrab, L., \& Centannia, S. (2006). Anxiety and Depression in COPD Patients: The Roles of Gender and Disease Severity. Respiratory Medicine, 100, 17671774. http://dx.doi.org/10.1016/j.rmed.2006.01.026

Doumit, J., \& Nasser, R. (2010). Quality of Life and Wellbeing of the Elderly in Lebanese Nursing Homes. International Journal of Health Care, 23, 72-93. http://dx.doi.org/10.1108/09526861011010695 
Frasure-Smith, N., \& Lespérance, F. (2006). Recent Evidence Linking Coronary Heart Disease and Depression. The Canadian Journal of Psychiatry, 51, 730-737.

Freedland, K. E., Rich, M. W., Skala, J. A., Carney, R. M., Dávila-Román, V. G., \& Jaffe, A. S. (2003). Prevalence of Depression in Hospitalized Patients with Congestive Heart Failure. Psychosomatic Medicine, 65, 119-128. http://dx.doi.org/10.1097/01.PSY.0000038938.67401.85

Gottlieb, S., Khatta, M., Friedmann, E., Einbinder, L., Katzen, S., Baker, B. et al. (2004). The Influence of Age, Gender, and Race on the Prevalence of Depression in Heart Failure Patients. Journal of the American College of Cardiology, 43, 15421549. http://dx.doi.org/10.1016/j.jacc.2003.10.064

Hamdan-Mansour, A., Constantino, R., Shishani, K., Safadi, R., \& Banimustafa, R. (2012). Evaluating the Psychological and Mental Consequences of Abuse among Abused Jordanian Women. Eastern Mediterranean Health Journal, 18, $205-212$.

Hamdan-Mansour, A. (2010). Predictors of Hostility among University Students in Jordan. Scandinavian Journal of Caring Sciences, 24, 125-130. http://dx.doi.org/10.1111/j.1471-6712.2009.00695.x

Hamdan-Mansour, A., Halabi, J., \& Dawani, H. (2009). Depression, Hostility, and Substance Use among University Students in Jordan. Mental Health and Substance Use: Dual Diagnosis, 2, 52-63. http://dx.doi.org/10.1080/17523280802593301

Honyashiki, M., Ferri, C. P., Acosta, D., Guerra, M., Huang, Y. et al. (2011). Chronic Diseases among Older People and Co-Resident Psychological Morbidity: A 10/66 Dementia Research Group Population-Based Survey. International Psychogeriatrics, 23, 1489-1501. http://dx.doi.org/10.1017/S1041610211000500

Hotopf, M., Chidgey, J., Addington-Hall, J., \& Ly, K. L. (2002). Depression in Advanced Disease: A Systematic Review, Part 1. Prevalence and Case Finding. Palliative Medicine, 16, 81-97. http://dx.doi.org/10.1191/02169216302pm507oa

Katon, W. (2003). Clinical and Health Services Relationships between Major Depression, Depressive Symptoms, and General Medical Illness. Biological Psychiatry, 54, 216-226. http://dx.doi.org/10.1016/S0006-3223(03)00273-7

Katon, W., Lin, E. H., \& Kroenke, K. (2007). The Association of Depression and Anxiety with Medical Symptom Burden in Patients with Chronic Medical Illness. General Hospital Psychiatry, 29, 147-155. http://dx.doi.org/10.1016/j.genhosppsych.2006.11.005

Lemyre, L., Tessier, R., \& Eillion, L. (1990). Mesure du stress psychotogique (MSP): Manuel d'utilisation [Psychological Stress Measure]. Brossard.

Lewinsohn, P. M., Hoberman, H., Teri, L., \& Hautzinger, M. (1985). An Integrative Theory of Depression. In S. Reiss, \& R. R. Bootzin (Eds.), Theoretical Issues in Behavior Therapy (pp 331-359). San Diego, CA: Academic Press.

Lustman, P. J., Anderson, R. J., Freedland, K. E., de Groot, M., Carney, R. M., \& Clouse, R. E. (2000). Depression and Poor Glycemic Control: A Meta-Analytic Review of the Literature. Diabetes Care, 23, 934-942. http://dx.doi.org/10.2337/diacare.23.7.934

Khalil, A., DarAwwad, M., Al-Gamal, E., Hamdan-Mansour, A., \& Abed, M. A. (2012). Predictors of Dietary and Fluid Non-Adherence in Jordanian Patients with End-Stage Renal Disease Receiving Haemodialysis: A Cross-Sectional Study. Journal of Clinical Nursing, 22, 127-136. http://dx.doi.org/10.1111/j.1365-2702.2012.04117.x

Mathers, C. D., \& Loncar, D. (2005). Updated Projections of Global Mortality and Burden of Disease 2002-2030: Data Sources, Methods and Results. Geneva: World Health Organization.

MacDonald, B. H. (2005). Quality of Life in Cancer Care: Patients' Experiences and Nurses' Contribution. European Journal of Oncology Nursing, 5, 32-41. http://dx.doi.org/10.1054/ejon.2000.0118

Moussavi, S., Chatterji, S., Verdes, E., Tandon, A., Patel, A., \& Ustun, B. (2007). Depression Chronic Diseases, and Decrements in Health: Results from the World Health Surveys. Lancet, 370, 851-858. http://dx.doi.org/10.1016/S0140-6736(07)61415-9

Sareen, J., Cox, B. J., Clara, I., \& Asmundson, G. (2005). The Relationship between Anxiety Disorders and Physical Disorders in the U.S. National Comorbidity Survey. Depression \& Anxiety, 21, 193-202. http://dx.doi.org/10.1002/da.20072

Scheier, M. F., Carver, C. S., \& Bridges, M. W. (1994). Distinguishing Optimism from Neuroticism (and Trait Anxiety, Self-Mastery, and Self-Esteem): A Reevaluation of the Life Orientation Test. Journal of Personality and Social Psychology, 67, 1063-1078. http://dx.doi.org/10.1037/0022-3514.67.6.1063

Sullivan, M., Simon, G., Spertus, J., \& Russo, J. (2002). Depression-Related Costs in Heart Failure Care. JAMA Internal Medicine, 162, 1860-1866. http://dx.doi.org/10.1001/archinte.162.16.1860

Wang, P. S., Demler, O., Olfson, M., Pincus, H. A., Wells, K. B., \& Kessler, R. C. (2006). Changing Profiles of Service Sectors Used for Mental Health Care in the United States. The American Journal of Psychiatry, 163, 1187-1198.

http://dx.doi.org/10.1176/appi.ajp.163.7.1187

WHO (World Health Organization) (2009). The Impact of Chronic Diseases Ion Jordan. Fact Sheet. http://www.who.int/chp/chronic_disease_report/en/ 
Yach, D., Hawkes, C., Gould, C., \& Hofman, K. (2004). The Global Burden of Chronic Diseases: Overcoming Impediments to Prevention and Control. Journal of the American Medical Association, 291, 2616-2622.

http://dx.doi.org/10.1001/jama.291.21.2616

Zhang, C. X., Chen, Y. M., \& Chen, W. Q. (2008). Association of Psychosocial Factors with Anxiety and Depressive Symptoms in Chinese Patients with Type 2 Diabetes. Diabetes Research and Clinical Practice, 79, 523-530. http://dx.doi.org/10.1016/j.diabres.2007.10.014

Zimet, G. D., Dahlem, N. W., Zimet, S. G., \& Farley, G. K. (1988). The Multidimensional Scale of Perceived Social Support. Journal of Personality Assessment, 52, 30-41. http://dx.doi.org/10.1207/s15327752jpa5201 2 
Scientific Research Publishing (SCIRP) is one of the largest Open Access journal publishers. It is currently publishing more than 200 open access, online, peer-reviewed journals covering a wide range of academic disciplines. SCIRP serves the worldwide academic communities and contributes to the progress and application of science with its publication.

Other selected journals from SCIRP are listed as below. Submit your manuscript to us via either submit@scirp.org or Online Submission Portal.
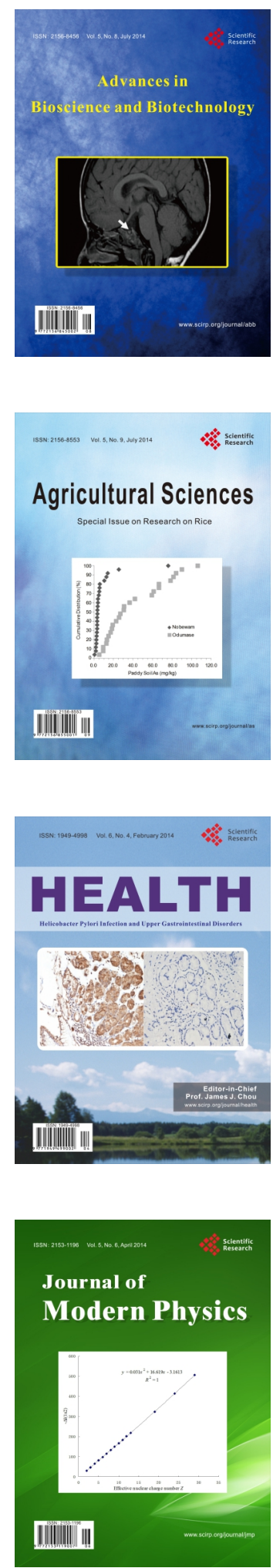
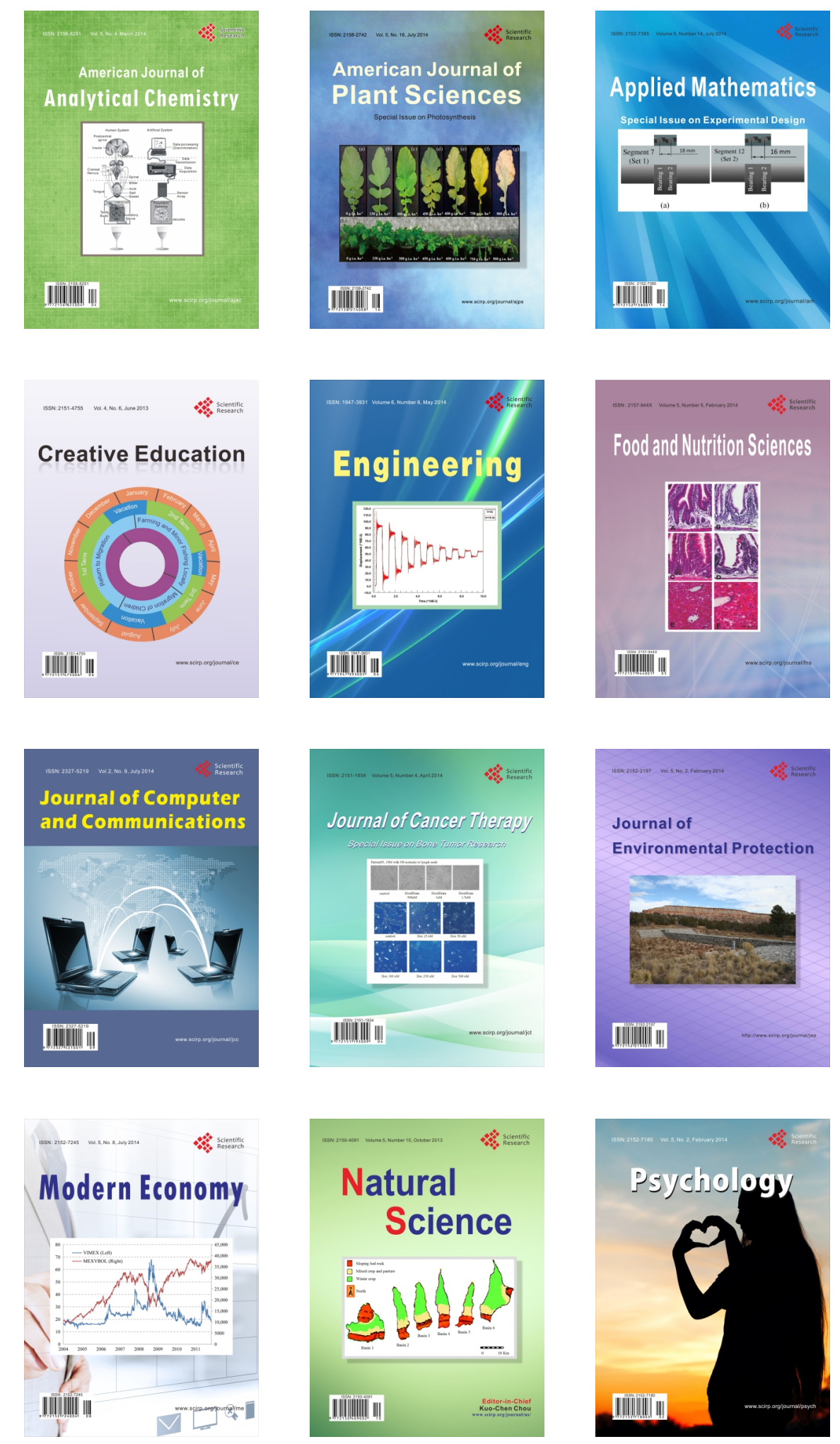